\title{
Optimal Uncertainty Decision of Innovation Products Output Based on Return Collection
}

\author{
Yi Su, ${ }^{1,2}$ Wei Sun, ${ }^{1,3}$ and Zhouzhou Lin ${ }^{1}$ \\ ${ }^{1}$ School of Economics and Management, Harbin Engineering University, Harbin 150001, China \\ ${ }^{2}$ School of Economics and Management, Tsinghua University, Beijing 10010, China \\ ${ }^{3}$ School of Science, Harbin Engineering University, Harbin 150001, China \\ Correspondence should be addressed to Yi Su; 13527715@qq.com
}

Received 20 June 2016; Revised 19 August 2016; Accepted 24 August 2016

Academic Editor: Xiaofeng Xu

Copyright (C) 2016 Yi Su et al. This is an open access article distributed under the Creative Commons Attribution License, which permits unrestricted use, distribution, and reproduction in any medium, provided the original work is properly cited.

\begin{abstract}
As the length of time between product renewals decreases, the enterprises that make innovative products face new challenges. The production cost structure of innovative products can be changed by collecting product returns, which can be economically valuable for enterprises. Enterprises face both production and demand randomness; hence, it is important to improve the traditional optimal production decision-making model that considers the randomness of demand only. This paper divides innovative products into structural innovation products and improved innovation products. The paper studies the optimal single-period production decision between reused parts and conventional new parts in complementary and substitute relationships. It further gives the analytical expressions for satisfying the optimal production and provides some numerical examples. The research results indicate that when producing innovative products, whether based on structural or improved innovation, with the variance of the quantity of the recycled parts increasing, the optimal purchase quantity of the conventional parts will increase but the expected profits for the innovative products will decrease. With integrated substitution and complementation based on improved innovation, enhancing the fluctuation in the number of recycled parts has a greater impact on the optimal purchase quantity of the substitute conventional parts than that of the complementary parts.
\end{abstract}

\section{Introduction}

The product production process is key to reducing an enterprise's inventory and to improving enterprise profitability, and there is much research on this issue. The accuracy of product output decisions has a significant impact on profitability. Some studies show that market demand uncertainty is a major factor in causing inaccurate output decisions in semiconductor manufacturing enterprises [1-3] and in seasonal product enterprises [4]. Decision-making models show that enterprises can establish an optimal output decision model in which market demand is in line with the normal distribution [4] based on the penalty coefficient of the market share and employee factors [5], on integration with the Monte-Carlo simulation method and a genetic algorithm, and on optimizing the product output $[6,7]$. Other studies investigate production in a multistage manufacturing system and in a three-stage supply chain made up of multiple suppliers, multiple manufacturers, and multiple markets [8] and use dynamic programming and recursive algorithms to determine the optimal production strategy at each stage [9] and the optimal distribution of the production of different products [10]. In addition to considering the impact of market demand, some studies consider the impact of defective products on production decisions [11, 12], especially for clothing, leather, stationery, and other traditional industries [13]. Based on whether product production is a multistage manufacturing system or a different production mode $[9$, $14-21]$, it is necessary to consider remanufacturing costs, inventory costs, and shortage costs $[22,23]$ and to make decisions in production planning and in production output when studying remanufacturing lot-sizing problems under an uncertain environment [24-27]. Worker errors [28, 29], machine breakdowns, and product rejects [30] can all cause defective products. The defective rate can be predicted using a support vector machine model based on statistical learning 
theory [31]. Using order production based on capacity constraints [11, 32], inventory control, and other methods [33, $34]$, enterprises can model and optimize their decisions on planning the quantity of products to produce [13, 35-39].

Traditionally, studies on enterprise management decisions focus on the cost optimization, enterprise production, inventory, and purchase decisions. As the product lifecycle becomes increasingly shorter, the amount of waste products generated has an increasingly serious impact on the environment. It is difficult for the innovative enterprise to balance enterprise development and environmental protection. The former strategy focuses on profit growth, while the latter focuses on sustainable development. Now, many enterprises must develop a product recycling strategy. Using recycled parts changes the enterprise cost structure. Such reuse can both meet environmental laws and other requirements and bring potential economic benefits. Generally, product output decisions do not account for the influence of recycled parts, an issue known as product reverse logistics [40]. Product reverse logistics means studying product output decisions while considering remanufacturing recycled products. Recycling for reuse is complex [41]. Considerations include the fixed-cost split between reuse and manufacturing [42], grading the recycled products to move from qualitative to quantitative production [43], and studying the interaction between manufacturing and reuse using a mixed integer linear programming model [44]. For production planning when reusing parts, it is necessary to consider the correlation between the parts [45] and the demand for shared parts by different products [46]. Hence, it is important to analyze the material recoverability rates when parts are dismantled [47], the remanufacturing rate, and the uncertainty of technology process [48]. The remanufacturing production planning is determined based on a production planning and scheduling model and state equation [49].

There are many decision-making studies on traditional product production. However, few studies focus on decisions relating to innovative product production. Unlike traditional products, enterprises often use new parts to produce innovative products. Innovative products are generally characterized by a short lifecycle and by rapid replacement. This situation generates a lot of waste, which is costly for the enterprises. Previous enterprise innovation studies do not have a micro focus, but rather they consider aspects such as the innovation preprocess and the relationship between innovation and enterprise performance. Those studies that investigate the commercialization process of innovation focus on the macro characteristics only, such as the impact of new products on the economy. This paper explores uncertainty decisions based on the innovative product output using recycled parts from a relatively micro perspective. Hence, under the uncertainty condition of the recycling of remanufacturing components, this paper considers the coordination between remanufacturing and new components.

\section{Model Assumption and Construction}

2.1. Model Assumption. The model assumes the following. The production, sales, recycling, and other relevant functions are accomplished independently by one enterprise. The enterprise is a centralized decision-making system. The cost of the recycled parts is $C_{r}$. The cost of the substitutive conventional parts is $C_{s}$. The cost of the complementary conventional parts is $C_{c}$.

The lifecycle of the innovative products is short. If such products have not sold out in a certain time period, then it is generally considered as an innovation failure. When the production exceeds the demand, the penalty value for each product is $s$. If the supply is inadequate to meet the demand, then it is generally considered as an innovation success. Demand fluctuation is represented by random variable $D$. The distribution function and the probability density function of $D$ are $F(\cdot)$ and $f(\cdot)$, respectively.

The number of recycled parts, represented by random variable $R$, cannot be accurately forecasted by the enterprises. The distribution function and the probability density function of $R$ are $F_{R}(\cdot)$ and $f_{R}(\cdot)$, respectively, independent of $D$. The enterprises cannot be artificially manipulated. The parameters do not change over time.

2.2. Model Construction. The enterprises that make innovative products use two methods: structural innovation and improved innovation. The products based on structural innovation are new products that are regrouped from existing parts. The products based on improved innovation are new products that require both old parts and some new parts. These two methods show that there is a substitutability or a complementary relationship between recycled parts and conventional new parts when the enterprises produce the innovative products. Under a substitutability condition, the innovative products are produced using recycled parts or using new parts purchased conventionally. Under a complementary condition, the innovative products are produced using both recycled parts and new parts purchased conventionally. Both are indispensable. This paper focuses on making decisions to optimize the profits of the enterprises that produce innovative products using these two methods.

(1) Part Substitution Based on Structural Innovation. If the number of recycled parts is $R$ and decision variable $q$ is the number of conventional new parts purchased by the enterprises (determined before $R$ ), then the final actual output is $R+q$. The output is obtained according to random demand $D$, and then sales revenue and cost are generated [50]. Here, the expected profit for the enterprise in producing innovative products is

$$
\begin{aligned}
& E\left(\Pi_{1}\right) \\
& \quad=E\left(p \min (R+q, D)-c_{s} q-c_{r} R-s(R+q-D)^{+}\right) .
\end{aligned}
$$

The following function is defined:

$$
(x)^{+}= \begin{cases}x, & x \geq 0 \\ 0, & x<0\end{cases}
$$

Figure 1 illustrates the relationship between actual demand $D$ and number of recovered parts $R$. 


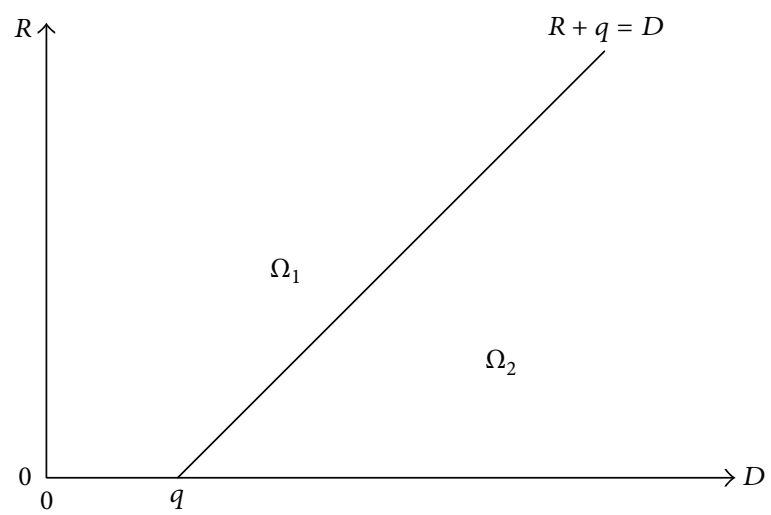

Figure 1: Relationship between demand $D$ and the number of recovered parts $R$.

Here, according to the division shown in Figure 1, the profit function can be expressed as

$\Pi_{1}$

$$
= \begin{cases}p D-c_{s} q-c_{r} R-s(R+q-D), & (R, D) \in \Omega_{1}, \\ p(R+q)-c_{s} q-c_{r} R, & (R, D) \in \Omega_{2} .\end{cases}
$$

(2) Part Complementarity Based on Improved Innovation. If the number of recycled parts is $R$ and decision variable $Q$ is the number of conventional new parts purchased by the enterprises (determined before $R$ ), then the final actual output is $\min (Q, R)$. The output is obtained according to random demand $D$, and then sales revenue and cost are generated. Here, the expected profit for the enterprise in producing innovative products is

$$
\begin{aligned}
& E\left(\Pi_{2}\right)=E\left(p \min (\min (Q, R), D)-c_{c} Q-c_{r} R\right. \\
& \left.-s(\min (Q, R)-D)^{+}\right) .
\end{aligned}
$$

Here, actual demand $D$ and number of recovered parts $R$ can be divided into four separate areas, as shown in Figure 2.

Here, according to the division in Figure 2, the profit function can be expressed as

$$
\Pi_{2}= \begin{cases}p D-c_{c} Q-c_{r} R-s(R-D), & (R, D) \in \Omega_{1}, \\ p D-c_{c} Q-c_{r} R-s(Q-D), & (R, D) \in \Omega_{2}, \\ p Q-c_{c} Q-c_{r} R, & (R, D) \in \Omega_{3}, \\ p R-c_{c} Q-c_{r} R, & (R, D) \in \Omega_{4} .\end{cases}
$$

(3) Integrated Substitution and Complementarity Model Based on Improved Innovation. If the number of recycled parts is $R$ and the decision variables $q$ and $Q$ are the number of substitute and complementary conventional new parts, respectively, purchased by the enterprises (determined before

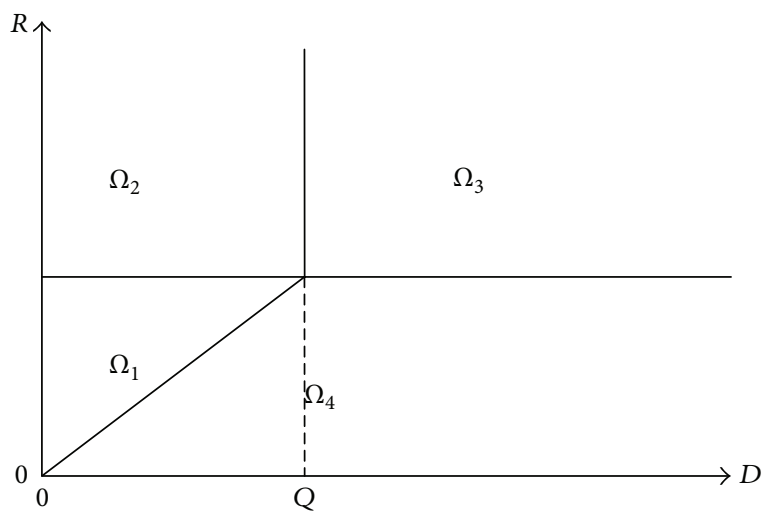

FIGURE 2: Relationship between demand $D$ and the number of recovered parts $R$.

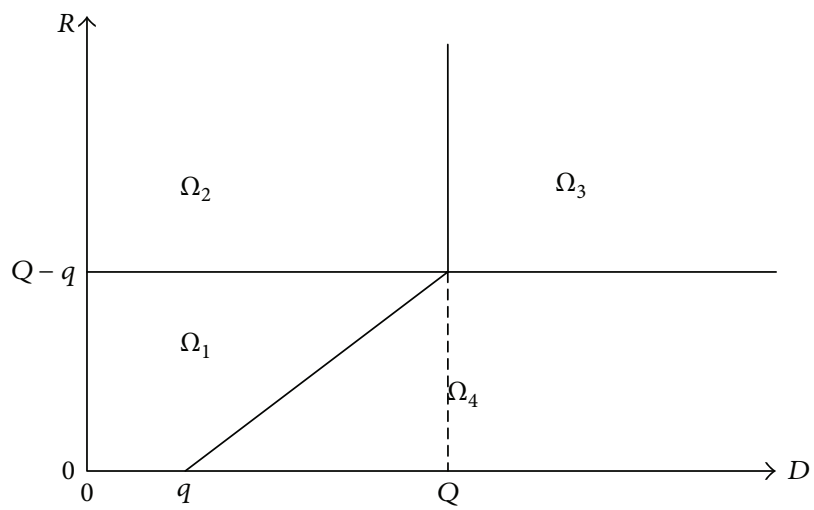

FIGURE 3: Relationship between demand $D$ and the number of recovered parts $R$.

$R)$, then the final actual output is $\min (Q, R+q)$. The output is obtained according to random demand $D$, and then sales revenue and cost are generated. Here, the expected profit for the enterprise in producing innovative products is

$$
\begin{aligned}
& E\left(\Pi_{3}\right)=E\left(p \min (\min (Q, R+q), D)-c_{c} Q-c_{s} q\right. \\
& \left.-c_{r} R-s(\min (Q, R+q)-D)^{+}\right) .
\end{aligned}
$$

Here, actual demand $D$ and number of recovered parts $R$ can be divided into four separate areas, as shown in Figure 3.

Here, according to the division in Figure 3, the profit function can be expressed as

$\Pi_{3}$

$$
= \begin{cases}p D-c_{c} Q-c_{s} q-c_{r} R-s(R+q-D), & (R, D) \in \Omega_{1}, \\ p D-c_{c} Q-c_{s} q-c_{r} R-s(Q-D), & (R, D) \in \Omega_{2}, \\ p Q-c_{c} Q-c_{s} q-c_{r} R, & (R, D) \in \Omega_{3}, \\ p(R+q)-c_{c} Q-c_{s} q-c_{r} R, & (R, D) \in \Omega_{4} .\end{cases}
$$




\section{Model Solution}

3.1. Optimal Decision for Part Substitution Based on Structural Innovation. The profit function can be expressed as

$\Pi_{1}$

$$
= \begin{cases}p D-c_{s} q-c_{r} R-s(R+q-D), & (R, D) \in \Omega_{1}, \\ p(R+q)-c_{s} q-c_{r} R, & (R, D) \in \Omega_{2} .\end{cases}
$$

Thus, the expected profit $E\left(\Pi_{1}\right)$ is

$$
\begin{aligned}
& E\left(\Pi_{1}\right)=\iint_{\Omega_{1} \cup \Omega_{2}} \Pi_{1} f_{D}(D) f_{R}(R) d \Omega \\
& =\iint_{\Omega_{1}}\left[p D-c_{s} q-c_{r} R-s(R+q-D)\right] f_{D}(D) \\
& \quad \cdot f_{R}(R) d \Omega+\iint_{\Omega_{2}}\left[p(R+q)-c_{s} q-c_{r} R\right] \\
& \quad \cdot f_{D}(D) f_{R}(R) d \Omega .
\end{aligned}
$$

In this formula, $\iint_{\Omega_{1}}\left[p D-c_{s} q-c_{r} R-s(R+q-\right.$ $D)] f_{D}(D) f_{R}(R) d \Omega$ is the expected profit of the enterprise when $R$ and $D$ intersection falls in area $\Omega_{1}$ in Figure 1 . Further, $\iint_{\Omega_{2}}\left[p(R+q)-c_{s} q-c_{r} R\right] f_{D}(D) f_{R}(R) d \Omega$ is the expected profit of the enterprise when $R$ and $D$ intersection falls in area $\Omega_{2}$ in Figure 1 [50].

So, we can get

$$
\begin{aligned}
E\left(\Pi_{1}\right)= & p \iint_{\Omega_{1}} f_{D}(D) f_{R}(R) d \Omega \\
& +p \iint_{\Omega_{1}}(R+q) f_{D}(D) f_{R}(R) d \Omega-c_{s} q \\
& -c_{r} \iint_{\Omega_{1} \cup \Omega_{2}} R f_{D}(D) f_{R}(R) d \Omega \\
& -s \iint_{\Omega_{1}}(R+q-D) f_{D}(D) f_{R}(R) d \Omega .
\end{aligned}
$$

To find optimal decision $q$, it is necessary to calculate the first-order derivative and the second-order derivative of the expected profit. Specifically,

$$
\begin{aligned}
\frac{d E\left(\Pi_{1}\right)}{d q}= & p \int_{0}^{+\infty} \overline{F_{D}(R+q)} f_{R}(R) d R-c_{s} \\
& -s \int_{0}^{+\infty} F_{D}(R+q) f_{R}(R) d R \\
= & \left(p-c_{s}\right) \\
& -(p+s) \int_{0}^{+\infty} F_{D}(R+q) f_{R}(R) d R \\
\frac{d^{2} E\left(\Pi_{1}\right)}{d q^{2}}= & -(p+s) \int_{0}^{+\infty} f_{D}(R+q) f_{R}(R) d R<0 .
\end{aligned}
$$

In this formula, $\overline{F(x)}=\int_{x}^{+\infty} f(x) d x$.
Obviously, expected profit $E\left(\Pi_{1}\right)$ meets the concave function requirement for $q$. Thus, the maximum point of $E\left(\Pi_{1}\right)$ can be acquired by $d E\left(\Pi_{1}\right) / d q=0$. Therefore, we have the following.

Proposition 1. Optimal purchase quantity $q$ of the conventional parts based on structural innovation in the case of part substitution is determined by the following formula:

$$
\int_{0}^{+\infty} F_{D}(R+q) f_{R}(R) d R=\frac{p-c_{s}}{p+s} .
$$

3.2. Optimal Decision for Part Complementarity Based on Improved Innovation. The profit function can be expressed as

$$
\Pi_{2}= \begin{cases}p D-c_{c} Q-c_{r} R-s(R-D), & (R, D) \in \Omega_{1}, \\ p D-c_{c} Q-c_{r} R-s(Q-D), & (R, D) \in \Omega_{2}, \\ p Q-c_{c} Q-c_{r} R, & (R, D) \in \Omega_{3}, \\ p R-c_{c} Q-c_{r} R, & (R, D) \in \Omega_{4} .\end{cases}
$$

Thus, expected profit $E\left(\Pi_{2}\right)$ is

$$
\begin{aligned}
& E\left(\Pi_{2}\right)=\iint_{\Omega_{1} \cup \Omega_{2} \cup \Omega_{3} \cup \Omega_{4}} \Pi_{2} f_{D}(D) f_{R}(R) d \Omega \\
& =\iint_{\Omega_{1}}\left[p D-c_{c} Q-c_{r} R-s(R-D)\right] f_{D}(D) \\
& \cdot f_{R}(R) d \Omega \\
& +\iint_{\Omega_{2}}\left[p D-c_{c} Q-c_{r} R-s(Q-D)\right] f_{D}(D) \\
& \cdot f_{R}(R) d \Omega+\iint_{\Omega_{3}}\left[p Q-c_{c} Q-c_{r} R\right] f_{D}(D) \\
& \cdot f_{R}(R) d \Omega+\iint_{\Omega_{4}}\left[p R-c_{c} Q-c_{r} R\right] f_{D}(D) \\
& \cdot f_{R}(R) d \Omega .
\end{aligned}
$$

So, we can get

$$
\begin{aligned}
E\left(\Pi_{2}\right)= & p \iint_{\Omega_{1} \cup \Omega_{2}} D f_{D}(D) f_{R}(R) d \Omega \\
& +p \iint_{\Omega_{3}} Q f_{D}(D) f_{R}(R) d \Omega \\
& +p \iint_{\Omega_{4}} R f_{D}(D) f_{R}(R) d \Omega-c_{c} Q \\
& -c_{r} \iint_{\Omega_{1} \cup \Omega_{2} \cup \Omega_{3} \cup \Omega_{4}} R f_{D}(D) f_{R}(R) d \Omega \\
& -s \iint_{\Omega_{1}}(R-D) f_{D}(D) f_{R}(R) d \Omega \\
& -s \iint_{\Omega_{2}}(Q-D) f_{D}(D) f_{R}(R) d \Omega .
\end{aligned}
$$


To find optimal decision $Q$, it is necessary to calculate the first-order derivative and the second-order derivative of expected profit $E\left(\Pi_{2}\right)$. Specifically,

$$
\begin{aligned}
\frac{d E\left(\Pi_{2}\right)}{d q}= & p \overline{F_{D}(Q) F_{R}(Q)}-c_{c}-s F_{D}(Q) \overline{F_{R}(Q)}, \\
\frac{d^{2} E\left(\Pi_{2}\right)}{d q^{2}}= & -(p+s) f_{D}(Q) \overline{F_{R}(Q)} \\
& -\left(p-(p+s) F_{D}(Q)\right) f_{R}(Q) .
\end{aligned}
$$

After the calculation, the root of $d E\left(\Pi_{2}\right) / d Q=0$ is $Q^{*}$, which satisfies the equation of $F_{D}\left(Q^{*}\right)=\left(p \overline{F_{R}\left(Q^{*}\right)}-c_{c}\right) /(p+$ s) $\overline{F_{R}\left(Q^{*}\right)}$. Thus,

$$
(p+s) F_{D}\left(Q^{*}\right)=\frac{p \overline{F_{R}\left(Q^{*}\right)}-c_{c}}{\overline{F_{R}\left(Q^{*}\right)}}=p-\frac{c_{c}}{\overline{F_{R}\left(Q^{*}\right)}}<p .
$$

Accordingly, if $\left.\left(d E\left(\Pi_{2}\right) / d Q\right)\right|_{\mathrm{Q}=Q^{*}}=0$, then $\left(d^{2} E\left(\Pi_{2}\right) /\right.$ $\left.d Q^{2}\right)\left.\right|_{Q=Q^{*}}<0$. So, $Q^{*}$ can maximize expected profit $E\left(\Pi_{2}\right)$.

Proposition 2. The optimal purchase quantity $Q$ of the conventional parts based on improved innovation in the case of part complementarity is determined by the following formula:

$$
p \overline{F_{D}(Q) F_{R}(Q)}-c_{c}-s F_{D}(Q) \overline{F_{R}(Q)}=0 .
$$

3.3. Optimal Decision for the Integrated Model with Substitution and Complementarity Based on Improved Innovation. The profit function can be expressed as

$$
\begin{aligned}
& \Pi_{3} \\
& = \begin{cases}p D-c_{c} Q-c_{s} q-c_{r} R-s(R+q-D), & (R, D) \in \Omega_{1}, \\
p D-c_{c} Q-c_{s} q-c_{r} R-s(Q-D), & (R, D) \in \Omega_{2}, \\
p Q-c_{c} Q-c_{s} q-c_{r} R, & (R, D) \in \Omega_{3}, \\
p(R+q)-c_{c} Q-c_{s} q-c_{r} R, & (R, D) \in \Omega_{4} .\end{cases}
\end{aligned}
$$

Thus, the expected profit $E\left(\Pi_{3}\right)$ is

$$
\begin{aligned}
& E\left(\Pi_{3}\right)=\iint_{\Omega_{1} \cup \Omega_{2} \cup \Omega_{3} \cup \Omega_{4}} \Pi_{3} f_{D}(D) f_{R}(R) d \Omega \\
& \quad=\iint_{\Omega_{1}}\left[p D-c_{c} Q-c_{s} q-s(R+q-D)\right] f_{D}(D) \\
& \quad \cdot f_{R}(R) d \Omega \\
& \quad+\iint_{\Omega_{2}}\left[p D-c_{c} Q-c_{s} q-c_{r} R-s(Q-D)\right] f_{D}(D) \\
& \quad \cdot f_{R}(R) d \Omega+\iint_{\Omega_{3}}\left[p Q-c_{c} Q-c_{s} q-c_{r} R\right] \\
& \quad \cdot f_{D}(D) f_{R}(R) d \Omega \\
& \quad+\iint_{\Omega_{4}}\left[p(R+q)-c_{c} Q-c_{s} q-c_{r} R\right] f_{D}(D) \\
& \quad \cdot f_{R}(R) d \Omega .
\end{aligned}
$$

So, we can get

$$
\begin{aligned}
E\left(\Pi_{3}\right)= & p \iint_{\Omega_{1} \cup \Omega_{2}} D f_{D}(D) f_{R}(R) d \Omega \\
& +p \iint_{\Omega_{3}} Q f_{D}(D) f_{R}(R) d \Omega \\
& +p \iint_{\Omega_{4}}(R+q) f_{D}(D) f_{R}(R) d \Omega-c_{c} Q \\
& -c_{s} q-c_{r} \iint_{\Omega_{1} \cup \Omega_{2} \cup \Omega_{3} \cup \Omega_{4}} R f_{D}(D) f_{R}(R) d \Omega \\
& -s \iint_{\Omega_{1}}(R+q-D) f_{D}(D) f_{R}(R) d \Omega \\
& -s \iint_{\Omega_{2}}(Q-D) f_{D}(D) f_{R}(R) d \Omega .
\end{aligned}
$$

To find optimal decisions $Q$ and $q$, it is necessary to calculate the first-order derivative and the second-order derivative of expected profit $E\left(\Pi_{3}\right)$. Specifically,

$$
\begin{aligned}
& \frac{\partial E\left(\Pi_{3}\right)}{\partial Q}=p \overline{F_{D}(Q) F_{R}(Q-q)}-c_{c}-s F_{D}(Q) \\
& \cdot \overline{F_{R}(Q-q)}, \\
& \frac{\partial E\left(\Pi_{3}\right)}{\partial q}=p \int_{0}^{Q-q} \overline{F_{D}(Q) F_{R}(Q-q)} f_{R}(R) d R-c_{s} \\
& -s \int_{0}^{\mathrm{Q}-q} F_{D}(R+q) f_{R}(R) d R, \\
& \frac{\partial^{2} E\left(\Pi_{3}\right)}{\partial Q^{2}}=-(p+s) f_{D}(Q) \overline{F_{R}(Q-q)}-(p \\
& \left.-(p+s) F_{D}(Q)\right) f_{R}(Q-q), \\
& \frac{\partial^{2} E\left(\Pi_{3}\right)}{\partial q^{2}}=-p \overline{F_{D}(Q)} f_{R}(Q-q) \\
& -p \int_{0}^{Q-q} f_{D}(R+q) f_{R}(R) d R \\
& -s\left[-F_{D}(Q) f_{R}(Q-q)\right. \\
& \left.+\int_{0}^{Q-q} f_{D}(R+q) f_{R}(R) d R\right], \\
& \frac{\partial^{2} E\left(\Pi_{3}\right)}{\partial Q \partial q}=\frac{\partial^{2} E\left(\Pi_{3}\right)}{\partial q \partial Q}=-p \overline{F_{D}(Q)} f_{R}(Q-q) \\
& -s F_{D}(Q) f_{R}(Q-q) \text {. }
\end{aligned}
$$


If $Q^{*}$ and $q^{*}$ satisfy the equations of $\partial E\left(\Pi_{3}\right) / \partial Q=0$ and $\partial E\left(\Pi_{3}\right) / \partial q=0$, then

$$
\begin{aligned}
& F_{D}\left(Q^{*}\right)=\frac{p \overline{F_{R}\left(Q^{*}-q^{*}\right)}-c_{c}}{(p+s) \overline{F_{R}\left(Q^{*}-q^{*}\right)}}, \\
& p \overline{F_{R}\left(Q^{*}-q^{*}\right)}-c_{s} \\
& \quad-(p+s) \int_{0}^{Q^{*}-q^{*}} F_{D}\left(R+q^{*}\right) f_{R}(R) d R=0 .
\end{aligned}
$$

It can be verified that $\left.\left(\partial^{2} E\left(\Pi_{2}\right) / \partial Q^{2}\right)\right|_{\substack{Q=Q^{*} \\ q=q^{*}}}<0$, $\left.\left(\partial^{2} E\left(\Pi_{2}\right) / \partial q^{2}\right)\right|_{\substack{\mathrm{Q}=Q^{*} \\ q=q^{*}}}<0,\left.\left(\partial^{2} E\left(\Pi_{2}\right) / \partial Q \partial q\right)\right|_{\substack{\mathrm{Q}=Q^{*} \\ q=q^{*}}}>0$, and

$$
\left.\left[\frac{\partial^{2} E\left(\Pi_{2}\right)}{\partial Q^{2}} \frac{\partial^{2} E\left(\Pi_{2}\right)}{\partial q^{2}}-\left(\frac{\partial^{2} E\left(\Pi_{2}\right)}{\partial Q \partial q}\right)^{2}\right]\right|_{\substack{Q=Q^{*} \\ q=q^{*}}}>0
$$

So, $Q^{*}$ and $q^{*}$ can maximize expected profit $E\left(\Pi_{3}\right)$. Therefore, we have the following.

Proposition 3. Optimal purchase quantities $Q^{*}$ and $q^{*}$ of the substitute and the complementary conventional parts, based on improved innovation in the case of integrated substitution and complementarity, are determined by the following formula:

$$
\begin{aligned}
& F_{D}\left(Q^{*}\right)=\frac{p \overline{F_{R}\left(Q^{*}-q^{*}\right)}-c_{c}}{(p+s) \overline{F_{R}\left(Q^{*}-q^{*}\right)}}, \\
& p \overline{F_{R}\left(Q^{*}-q^{*}\right)}-c_{s} \\
& \quad-(p+s) \int_{0}^{Q^{*}-q^{*}} F_{D}\left(R+q^{*}\right) f_{R}(R) d R=0 .
\end{aligned}
$$

\section{Numerical Analysis}

4.1. Numerical Simulation of Part Substitution Based on Structural Innovation. The influence that part recovery uncertainty has on the optimal solution can be studied by setting the values of some parameters. According to [50], $p=10$, $g=8, s=2, C_{c}=3, C_{r}=2, D \sim N(90,15)$. Here, production depends on recycled parts and conventional new parts. Accordingly, this paper sets $R$ to accord with normal distribution, the mean value as $\mu$, and the variance as $\sigma^{2}$ and takes $\mu=50$ into account. To observe the influence of the range of numerical values in $\sigma^{2}$ on the optimal strategy and profit, this paper adjusts variance $\sigma^{2}$. The results are shown in Table 1 .

From Table 1, for the certain value of $\mu$, the optimal purchase quantity of the substitute conventional parts based on improved innovation will increase. However, the expected profits of the innovative products will decrease, as the variance of recycled quantity $R$ increases.

4.2. Numerical Simulation of Part Complementarity Based on Improved Innovation. Producing innovative products relies entirely on recycled parts. However, in the actual production,
TABLE 1: Optimal strategy and profit by recovered quantity: part substitution.

\begin{tabular}{lcc}
\hline Variance & $\begin{array}{c}\text { The quantity of } \\
\text { substitution parts } q\end{array}$ & Profit \\
\hline 6 & 40.44 & 656.34 \\
8 & 40.46 & 655.24 \\
10 & 40.48 & 654.19 \\
12 & 40.50 & 653.18 \\
14 & 40.52 & 652.20 \\
16 & 40.54 & 651.26 \\
18 & 40.55 & 650.35 \\
20 & 40.57 & 649.46 \\
\hline
\end{tabular}

the enterprises keep the production scale of the recycled parts close to the demand scale. Here, this paper sets $R$ to accord with the normal distribution, the mean value as $\mu$, and the variance as $\sigma^{2}$ and takes $\mu=90$ into account. To observe the influence of the range of numeric values in $\mu$ and $\sigma^{2}$ on the optimal strategy and profit, this paper adjusts mean value $\mu$ and variance $\sigma^{2}$. Table 2 shows the results.

Table 2 shows that, for certain $\mu$ values, the optimal purchase quantity of the complementary conventional parts based on improved innovation will increase. However, the expected profits for the innovative products will decrease as recycled quantity $R$ increases. Table 2 also shows that, for certain $\sigma^{2}$ values, the optimal purchase quantity of the complementary conventional parts based on improved innovation will increase as $\mu$ value increases. When $\mu$ value is close to average $D$ value, then the expected profit will reach its maximum.

This means that if the expected supply quantity is a certain value, with the supply risk increasing, then the effective output will decrease and will need to be compensated by increasing the purchasing quantity. The profits of the innovation products will decrease as the uncertainty increases. Additionally, if the supply risk of the recycled parts is certain, when the expected supply quantity increases, the optimal purchase quantity of the complementary conventional parts will increase. When the expected supply quantity of the recycled parts is close to the expected demand quantity, the expected profits of the innovative products can reach the maximum.

4.3. Numerical Simulation under Integrated Substitution and Complementarity Based on Improved Innovation. Parts can be obtained by substitution or by complementarity when producing products based on improved innovation. If $c_{s}=3$ and $R$ accords with the normal distribution, then the mean value is $\mu=50$ and the variance is $\sigma^{2}$. The other parameters are the same as those in Section 4.2. To observe the influence of $\sigma^{2}$ values on the optimal strategy and profit, this paper adjusts variance $\sigma^{2}$. Table 3 shows the results.

From Table 3 , if $\mu=50$, then the optimal purchase quantity of both the substitute and the complementary parts will increase. However, the expected profits of the innovative products will decrease as the variance of $R$ increases. This 
TABLE 2: Optimal strategy and profit by recovered quantity: part complementarity.

\begin{tabular}{lcccccc}
\hline Variance $\sigma^{2}$ & $\begin{array}{c}\text { Quantity } \\
\text { demanded Q }\end{array}$ & $\begin{array}{c}\text { Expected } \\
\text { profits }\end{array}$ & $\begin{array}{c}\text { Quantity } \\
\text { demanded } Q\end{array}$ & $\begin{array}{c}\mu=90 \\
\text { Expected } \\
\text { profits }\end{array}$ & $\begin{array}{c}\mu=100 \\
\text { Quantity } \\
\text { demanded Q }\end{array}$ & $\begin{array}{c}\text { Expected } \\
\text { profits }\end{array}$ \\
\hline 6 & 100.00 & 239.69 & 104.00 & 280.23 & 113.50 & 215.69 \\
8 & 100.00 & 239.58 & 105.46 & 273.27 & 116.00 & 205.58 \\
10 & 100.00 & 239.45 & 107.00 & 266.07 & 118.50 & 195.45 \\
12 & 100.00 & 239.30 & 109.00 & 257.05 & 118.50 & 195.30 \\
14 & 100.00 & 239.14 & 110.00 & 252.07 & 121.00 & 185.14 \\
16 & 102.00 & 230.96 & 112.00 & 243.12 & 122.25 & 179.96 \\
18 & 103.00 & 226.76 & 113.00 & 238.21 & 128.50 & 154.76 \\
20 & 104.00 & 222.56 & 114.00 & 233.32 & 128.50 & 154.56 \\
\hline
\end{tabular}

TABLE 3: Optimal strategy and profit by recovered quantity: integrated substitution and complementarity.

\begin{tabular}{lccc}
\hline Variance & $\begin{array}{c}\text { Quantity of } \\
\text { substitute part } q\end{array}$ & $\begin{array}{c}\text { Quantity of } \\
\text { complementary } \\
\text { part Q }\end{array}$ & Profit \\
\hline 6 & 38.41 & 87.66 & 297.32 \\
8 & 38.61 & 87.71 & 296.11 \\
10 & 38.79 & 87.74 & 295.03 \\
12 & 38.95 & 87.77 & 294.04 \\
14 & 39.09 & 87.80 & 293.13 \\
16 & 39.23 & 87.82 & 292.28 \\
18 & 39.36 & 87.84 & 291.48 \\
20 & 39.48 & 87.86 & 290.72 \\
\hline
\end{tabular}

shows that, to ensure a sufficient output, the purchase quantity of conventional parts will increase, but the expected profits of the innovative products will decrease, as the supply risk of the recycled parts increases. Through the above analysis, an increased fluctuation in the quantity of recycled parts means that the enterprises need gradually decreasing quantities of conventional parts, and the profits for the innovative products also decrease. Analyzing the results shows that an increased fluctuation in $R$ has a greater impact on the optimal purchase quantity of the substitute conventional parts than that of the complementary parts.

\section{Conclusion}

This paper studies the optimal output decision for innovative products when the quantity of the recycled parts is uncertain. The model aims to maximize the expected profits for innovative products, accounting for both recycled parts and conventional parts. The model analyzes the optimal decision strategy when the recycled parts and the conventional parts are in a substitute relationship and a complementary relationship, namely, under the circumstances of structural innovation and improved innovation. This paper gives the analytic expressions to meet the optimal production quantity and analyzes the relationship between the optimal production quantity and various parameters. When an enterprise produces innovative products-whether based on structural innovation or improved innovation - as the variance of the quantity of the recycled parts increases, the optimal purchase quantity of the conventional parts will increase but the expected profits of the innovative products will decrease. For integrated substitution and complementarity circumstances in cases of improved innovation, fluctuations in the number of recycled parts have a greater impact on the optimal purchase quantity of the substitute conventional parts than that of the complementary parts. In reality, using recycled parts will effectively reduce costs when enterprises produce innovative products. However, fluctuations in the number of available recycled parts will have an impact on the procurement of other parts. When enterprises make decisions about producing innovative products, they should consider the influence of uncertainties in the supply of recycled parts on the expected profits of the innovative products. This study has some shortcomings. The study only discusses the optimal decision in a single period. A multiperiod analysis would more accurately reflect the reality and should be the subject of a further study.

\section{Competing Interests}

The authors declare that there is no conflict of interests regarding the publication of this paper.

\section{Acknowledgments}

This work was supported by the National Natural Science Foundation of China (71403066); the State Key Program of National Social Science of China (14AGL004); the Fund of Ministry of Education of China (20122304120021); China Postdoctoral Science Foundation (2013T60351); the Special Foundation of Central Universities Basic Research Fee (HEUCF140907); Heilongjiang Province Postdoctoral Start Fund (LBH-Q13050); and the Scientific and Technological Projects of Heilongjiang Province (GZ11D203).

\section{References}

[1] B. Çatay, Ş. S. Erengüç, and A. J. Vakharia, "Tool capacity planning in semiconductor manufacturing," Computers \& Operations Research, vol. 30, no. 9, pp. 1349-1366, 2003. 
[2] S. J. Hood, S. Bermon, and F. Barahona, "Capacity planning under demand uncertainty for semiconductor manufacturing," IEEE Transactions on Semiconductor Manufacturing, vol. 16, no. 2, pp. 273-280, 2003.

[3] S. Karabuk and S. D. Wu, "Coordinating strategic capacity planning in the semiconductor industry," Operations Research, vol. 51, no. 6, pp. 839-849, 2003.

[4] L. Yong and C. Kai, "A production quantity-delivery time decision model for a two stage supply chain of seasonal items," Industrial Engineering and Management, no. 4, pp. 1-6, 2007.

[5] A. Corominas, A. Lusa, and R. Pastor, "Planning production and working time within an annualised hours scheme framework," Annals of Operations Research, vol. 155, no. 1, pp. 5-23, 2007.

[6] C. Liang, Z. Changlin, and W. Xiaojing, "Optimal production capacity in the system with multiple uncertain factors," Journal of Wut (Information \& Management Engineering), vol. 33, no. 2, pp. 275-279, 2011.

[7] W. Tao and H. Peiqing, "Procurement and production decisions for an assemble-to-order manufacturer with limited production capacity," Industrial Engineering and Management, vol. 13, no. 5, pp. 11-14, 2008.

[8] Q.-Z. Ma, H.-Q. Song, and G.-Y. Chen, "Research on pricing and production decision-making under the supply chain environment considering the carbon-trading mechanism," Chinese Journal of Management Science, vol. 22, no. 8, pp. 37-46, 2014.

[9] J. Hwang and M. R. Singh, "Optimal production policies for multi-stage systems with setup costs and uncertain capacities," Management Science, vol. 44, no. 9, pp. 1279-1294, 1998.

[10] J. Guojun and L. Hua, "Systematic production allocation and remanufacturing decision of diversified product under stochastic condition," Statistics and Decision, no. 11, pp. 41-44, 2007.

[11] H. Shengqiang, Z. Bixi, L. Zhaohui, and C. Shuo, "Decision of materials planning quantities based on random nonconforming finished goods and rework under the MTO mode," Industrial Engineering and Management, vol. 20, no. 5, pp. 71-79, 2015.

[12] H. Shengqiang, Z. Bixi, Z. Xiangwei, and L. Zhaohui, "Decisionmaking of planning input quantity based on qualified rate and effective rework rate," Mathematics in Practice and Theory, vol. 44, no. 8, pp. 1-9, 2014.

[13] Z. Bixi, S. Jing, and G. Liuying, "Decision-making of planning quantity put into production for make to order system," Systems Engineering-Theory \& Practice, vol. 28, no. 7, pp. 165-178, 2008.

[14] Y. C. Jiang, A. M. Zhang, and X. P. Song, "Study of production planning management systems in order driven medium and small enterprises," Machinery, vol. 9, pp. 60-63, 2005.

[15] L. Liu and E. S. Qi, "Research on applying method of APS in make-to-order production plant," Modular Machine Tool \& Automatic Manfacturing Technique, vol. 10, pp. 100-103, 2006.

[16] F. Caihong, Research and Application of Material RequirementsPlanning System in Little Batch Manufacturing Mode, Nanjing University of Aeronautics and Astronautics, Nanjing, China, 2005.

[17] F. Chunhua, S. Xuefeng, and H. Chao, "Single product, single supplier order quantity decision considering materials demand features of different production methods," Management Review, vol. 21, no. 4, pp. 111-119, 2009.

[18] Z. Hu, Study on Material Requirement Planning Optimization Based on Six Sigma, Huazhong University of Science \& Technology, Wuhan, China, 2012.
[19] Q. Wang, S.-A. Liu, B. Gao, and D. Wang, "A framework model of production planning optimization for make-to-order discrete manufacturing," in Proceedings of the Chinese Control and Decision Conference (CCDC '09), pp. 2516-2520, June 2009.

[20] Y. Ping, J. Jianhua, and G. Qiaolun, "Research on optimal model for two-period supplier production planning based on MC ," Journal of Chongqingjiaotong University, vol. 27, no. 4, pp. 661664, 2008.

[21] B.-X. Zhang, Y.-Y. Guan, and J. Song, "Optimization of batches processing modes for manual operating system considering learning rate," System Engineering Theory \& Practice, vol. 30, no. 4, pp. 622-627, 2010.

[22] W. Yanhua and C. Weida, "Lot sizing problem with remanufacturing under demand uncertainty," Journal of Systems \& Management, vol. 21, no. 2, pp. 270-274, 2012.

[23] Y. Jing, X. Wang, W.-C. Li, and L. Deng, "Remanufacturing lot sizing production planning considering product differentiation in multi-uncertain environment," Computer Integrated Manufacturing Systems, vol. 18, no. 12, pp. 2650-2658, 2012.

[24] C.-H. Yeh, "A customer-focused planning approach to make-toorder production," Industrial Management \& Data Systems, vol. 100, no. 4, pp. 180-187, 2000.

[25] S. Benjaafar and M. Elhafsi, "Production and inventory control of a single product assemble-to-order system with multiple customer classes," Management Science, vol. 52, no. 12, pp. 18961912, 2006.

[26] S. Deng and C. A. Yano, "Joint production and pricing decisions with setup costs and capacity constraints," Management Science, vol. 52, no. 5, pp. 741-756, 2006.

[27] Z. Renqian and X. Yiyong, "A research on agent-based heuristic production planning of product mix considering build-toorder," Systems Engineering Theory and Practice, no. 10, pp. 5462, 2007.

[28] L. Liu and E. S. Qi, "Research on applying method of APS in make-to-order production plant," Modular Machine Tool \& Automation Manufacturing Technique, vol. 10, pp. 100-103, 2006.

[29] B. Sarkar, S. S. Sana, and K. Chaudhuri, "An imperfect production process for time varying demand with inflation and time value of money-an EMQ model," Expert Systems with Applications, vol. 38, no. 11, pp. 13543-13548, 2011.

[30] S. W. Chiu, "An optimization problem of manufacturing systems with stochastic machine breakdown and rework process," Applied Stochastic Models in Business and Industry, vol. 24, no. 3, pp. 203-219, 2008.

[31] Z. Kuiling, Prediction of Product Qualified Rate Based on Support Vector Machine, South China University of Technology, Guangzhou, China, 2012.

[32] H. L. Gao, B. Dan, and Y. G. Jing, "A production planning model for make-to-order companies with capacity constraint," Advanced Materials Research, vol. 201-203, pp. 1066-1069, 2011.

[33] L. Qunxia and Z. Qun, "Fuzzy optimization of a production inventory system with allowable shortages and defective items," Systems Engineering Theory and Practice, vol. 31, no. 3, pp. 480486, 2011.

[34] S. Qin, L. Yongfei, and L. Weizu, "EOQ of manufacturer based on stochastic demand and material quality defect," Industrial Engineering and Management, vol. 16, no. 1, pp. 53-58, 2001.

[35] Z. Li, "Study on non-conformity product control during manufacturing process," Electronics Quality, vol. 9, pp. 44-46, 1999. 
[36] S. Shouxu, Z. Huabing, and F. Renjie, "Reverse logistics planning of un-standard products in mass production," Logistics Technology, no. 8, pp. 49-52, 2004.

[37] C. Jun, Study on the Price and Quality Level Decision-Making of Remanufactured Product in the Closed-Loop Supply Chain, Chongqing University, Chongqing, China, 2008.

[38] H. Shengqiang, Z. Bixi, and Z. Xiangwei, "Optimization of input quantities about MTO multi-stage production system based on qualified rate," Industrial Engineering and Management, vol. 17, no. 4, pp. 57-64, 2012.

[39] G. Huali, D. Bin, and Z. Xumei, "Decision-making model of planning quantity put into production for the make-to-order enterprises with limited capacity and shortage penalty cost," Industrial Engineering and Management, vol. 28, no. 3, pp. 4348, 2013.

[40] D. A. Schrady, "A deterministic inventory model for reparable items," Naval Research Logistics Quarterly, vol. 14, no. 3, pp. 391398, 1967.

[41] V. D. R. Guide, "Production planning and control for remanufacturing: industry practice and research needs," Journal of Operations Management, vol. 18, no. 4, pp. 467-483, 2000.

[42] R. H. Teunter, Z. P. Bayindir, and W. Van Den Heuvel, "Dynamic lot sizing with product returns and remanufacturing," International Journal of Production Research, vol. 44, no. 20, pp. 43774400, 2006.

[43] V. Jayaraman, "Production planning for closed-loop supply chains with product recovery and reuse: an analytical approach," International Journal of Production Research, vol. 44, no. 5, pp. 981-998, 2006.

[44] O. Tang and R. Teunter, "Economic lot scheduling problem with returns," Production and Operations Management, vol. 15, no. 4, pp. 488-497, 2006.

[45] S. M. Gupta and K. N. Taleb, "Scheduling disassembly," International Journal of Production Research, vol. 32, no. 8, pp. 18571866, 1994.

[46] K. N. Taleb and S. M. Gupta, "Disassembly of multiple product structures," Computers and Industrial Engineering, vol. 32, no. 4, pp. 949-961, 1997.

[47] V. D. R. Guide Jr. and M. S. Spencer, "Rough-cut capacity planning for remanufacturing firms," Production Planning and Control, vol. 8, no. 3, pp. 237-244, 1997.

[48] G. Ferrer and D. C. Whybark, "Material planning for a remanufacturing facility," Production and Operations Management, vol. 10, no. 2, pp. 112-124, 2001.

[49] Z.-Y. Cai, R.-B. Xiao, Y. Tan, and F.-M. Gong, "Fuzzy adaptive production plan dispatching of cycle supply chain under uncertainty conditions," Control and Decision, vol. 23, no. 5, pp. 525$529,2008$.

[50] W. Peng and C. Jian, "Optimal production decision with return collection uncertainty," Journal of Systems Engineering, vol. 23, no. 6, pp. 644-719, 2008. 

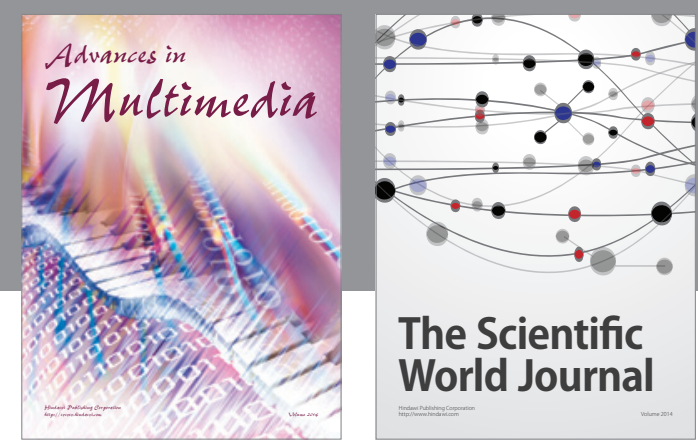

The Scientific World Journal
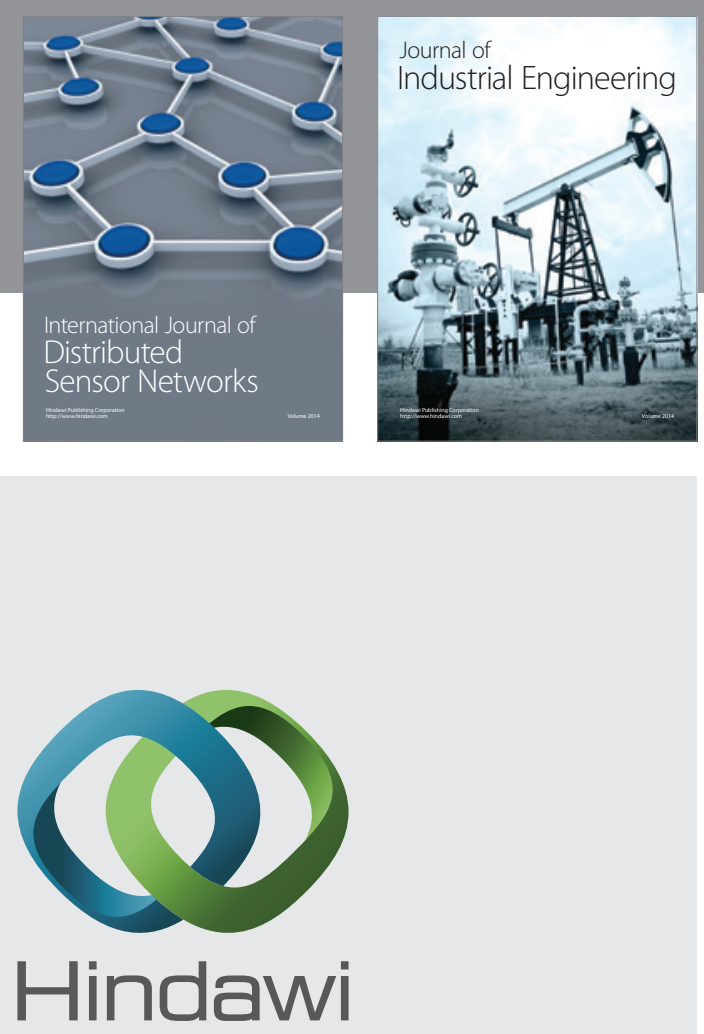

Submit your manuscripts at

http://www.hindawi.com

\section{Computer Networks} and Communications
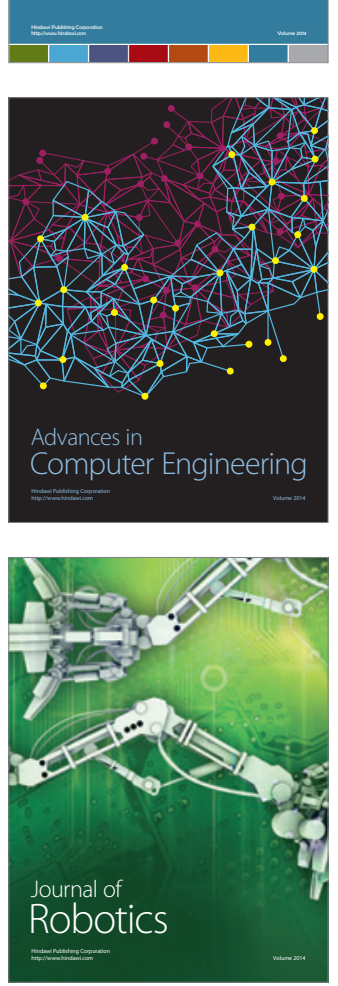
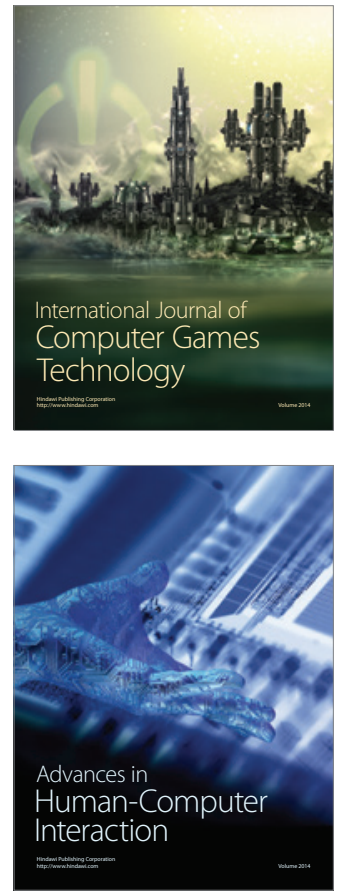
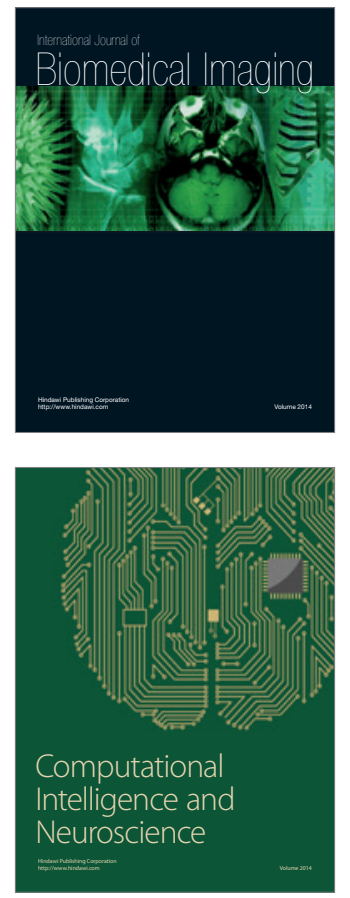
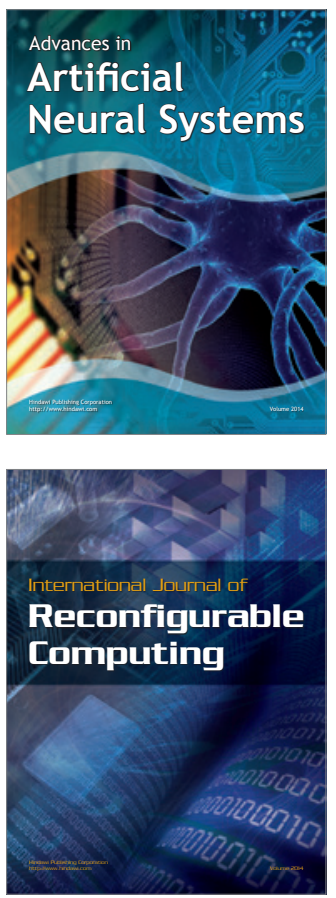
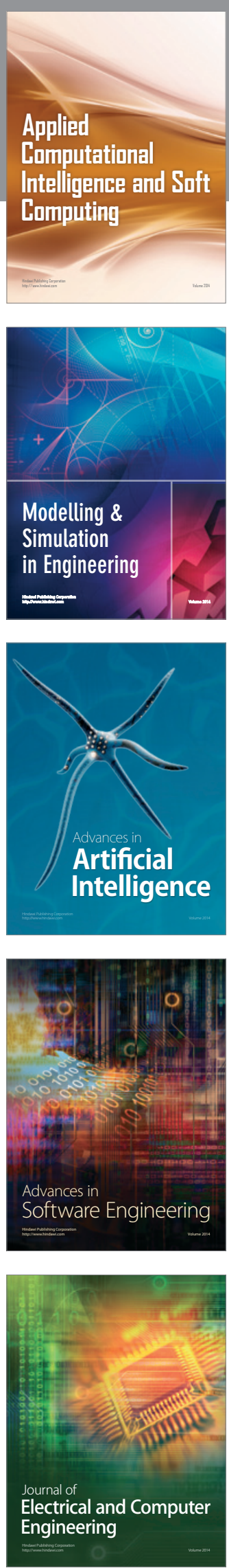